ISSN: $2317-8957$

\title{
AS TECNOLOGIAS DA INFORMAÇÃO E COMUNICAÇÃO COMO INSTRUMENTO DE INTERNACIONALIZAÇÃO CURRICULAR NA GRADUAÇÃO
}

\author{
AMANDA CRISTINE CORREAA LOPES BITENCOURT ${ }^{1,2}$ \\ ${ }^{1}$ Universidade Federal do Rio de Janeiro (UFRJ) \\ ${ }^{2}$ Secretaria do Estado de Educação do Rio de Janeiro (SEEDUC)
}

\begin{abstract}
RESUMO
Este artigo tem como objetivo analisar e compreender as interseções entre os resultados de internacionalização, as tecnologias da informação e comunicação (TICs) e o currículo planejado. Para explorar e entender essas interseções presentes no ambiente de ensino e aprendizagem de um currículo internacionalizado no ensino superior, essa pesquisa de caráter bibliográfico, ampara-se nos estudos de Betty Leask, Jos Bellen e Elspeth Jones. Como resultado, observa-se que as TICs oferecem muitas oportunidades para internacionalizar o currículo e as experiências de aprendizagem de estudantes, mas elas também oferecem desafios, pois o ensino alcança uma maior diversidade de alunos em um ambiente mais complexo e diverso de aprendizagem.

Palavras-chave: TICs, Internacionalização, Graduação
\end{abstract}

\begin{abstract}
This article aims to analyze and understand the intersections between internationalization results, information and communication technologies and the planned curriculum. To explore and understand these intersections present in the learning environment of an internationalized curriculum in higher education, this bibliographic research draws on the studies of Betty Leask, Jos Bellen, and Elspeth Jones. As result, it is noted that ICTs offer many opportunities to internationalize curriculum and student learning experiences, but they also present challenges as teaching reaches a wider diversity of learners in a more complex and diverse learning environment.

Keywords: ICT, Internationalization, graduation
\end{abstract}

\section{INTRODUÇÃO}

A globalização ocorrida, nas sociedades contemporâneas, surge como um fenômeno reestruturador da vida humana em todas as suas tarefas. Trata-se de um fenômeno que articula economia, tecnologia, política cultura, sociedade e espaço. (VIEIRA; VIEIRA; DA COSTA
KNOPP, 2010).

Da globalização decorrem articulações e transações que extrapolam a localidade, que ocorrem tanto entre as nações como além delas, criando e recriando as fronteiras. No ponto de vista de alguns teóricos da globalização, “o mundo tem aparentemente se tornado sem fron- 
teiras, apesar da existência continuada de fronteiras entre estados e todos os dispositivos administrativos que as mantêm" (CLEGG, 2003, p. 3).

Longe de ser singular, a globalização é plural, com características não lineares e assimétricas. É em si dialética, pois dela emergem diversidades, desigualdades, tensões, confluências, acomodações e contradições. É, concomitantemente, geradora de homogeneidades e heterogeneidades. "Se por um lado a globalização pressupõe uma homogeneização nas relações econômicas entre países, por outro, em termos práticos, prevalece uma heterogeneidade onde se aprofundam diferenças sociais internas e externas devido à concentração de riquezas" (MARIZ \& ANDRADE, 2006).

Também coexistem, em termos gerais, a unipolaridade (no sentido de predomínio) político-ideológica (capitalista neoliberal) que emana dos países cêntricos na economia mundial e a multipolaridade produtiva global. É por causa desses diferentes efeitos e das suas diversas facetas que autores como Boaventura Santos (2005) falam da existência de não apenas uma globalização, mas de múltiplas globalizações. A globalização, conforme o autor, implica na articulação entre diferentes escalas de poder, ou seja, na convergência e conflito entre a dimensão local e global dos lugares. A articulação local e global é uma das relações dialéticas da nova modernidade.

Nesse cenário, a globalização e a internacionalização estão relacionadas, mas não são a mesma coisa. A globalização é o contexto das tendências econômicas e educacionais que fazem parte do século XXI. A internacionalização inclui políticas e práticas adotadas pelos sistemas de ensino - e até mesmo pelos indivíduos - para lidar com o ambiente educacional global. (ALTBACH; KNIGHT, 2007).

As fronteiras entre o local, o nacional e o global foram redefinidas e o futuro, coletivo e individual, depende de quão flexíveis, abertos e criativos somos na maneira como pensamos, vivemos e trabalhamos. A globalização é agora considerada como "o fator contextual mais im- portante que molda a internacionalização da educação" (IAU, 2012, p.1).

Assim, há um sentimento de urgência em torno da necessidade de assegurar que a educação responda apropriadamente "às exigências e desafios associados à globalização da sociedade, da economia e do mercado de trabalho" (VAN DER, WENDE 1997, p.19). À medida que o mundo torna-se cada vez mais conectado e mais dividido, torna-se mais urgente a necessidade de se construir "pontes de tolerância e respeito por outras culturas" por meio da educação (KRAMSCH, 2002, p.272).

Porém, é um grande desafio assegurar que as escolas promovam e apoiem "o pensamento crítico e independente, juntamente com uma base de valores fortes de justiça social" (BOURN, 2010, P. 27), em um mundo cada vez mais dominado por interesses econômicos e não por interesses humanos e ambientais. A interação internacional e a colaboração por meio da educação têm o potencial de desenvolver uma visão e troca cultural que é enriquecedora e capacitadora para os indivíduos, comunidades, nações e o mundo. Elas oferecem uma maneira de identificar e abordar as questões associadas com a globalização e de lidar com as desigualdades, pois somente se desenvolvermos nos discentes a capacidade de criticar o mundo em que vivem, verão questões e problemas de uma série de perspectivas e tomarão medidas para enfrentá-los (LEASK, 2015).

Dessa forma, a intenção passa ser um currículo que promova uma compreensão intercultural, que incentive uma perspectiva internacional e ajude os estudantes a melhor entender o caráter complexo e diverso do ambiente global. Assim, o processo de internacionalização no campo curricular tem se fortalecido e intensificado significativamente nos últimos anos. (RIZVI, 2010; CARUANA e SPURLING, 2007; HARRIS, 2011, apud MOREIRA, 2012).

Nesse contexto, a internacionalização nas instituições está frequentemente focada no movimento de estudantes - atraindo estrangeiros para estudar, e encorajando estudantes da própria instituição a estudar fora do 
país. Além dessa possibilidade, as tecnologias de informação e comunicação trazem uma nova dimensão para a internacionalização do ensino. Elas estão sendo usadas para aumentar a qualidade de aprendizagem de todos estudantes, pois a grande maioria não tem oportunidades de mobilidade, o que levou as instituições escolares a buscarem valores, princípios e metas subjacentes à internacionalização por meio da internacionalização do currículo, bem como atividades extra curriculares, para que os estudantes não móveis- a grande maioria, também pudessem se beneficiar da internacionalização e ganhar as competências globais de que necessitarão. Nessa perspectiva, busca-se algumas soluções nas tecnologias para garantir esse acesso mais igualitário às oportunidades de internacionalização para todos os alunos, já que as tecnologias da informação e comunicação possibilitam interação com pessoas de diferentes instituições e localidades.

Assim, este artigo tem como objetivo analisar e compreender as intersecções entre os resultados de internacionalização, as tecnologias da informação e comunicação e o currículo planejado. Para compreender essas interseções presentes no ambiente de ensino e aprendizagem de um currículo internacionalizado, essa pesquisa de caráter bibliográfico, ampara-se nos estudos de Betty Leask, Jos Bellen e Elspeth Jones.

No entendimento teórico de internacionalização curricular, esse estudo ampara-se na definição de Leask, que define a internacionalização curricular como o processo de incorporação de uma dimensão internacional, intercultural e/ou global no conteúdo do currículo, bem como nos seus objetivos de aprendizagem, nas atividades de avaliação, na metodologia e em todos os serviços voltados ao curso". (LEASK, 2015, p. 9).

Assim, este presente artigo está dividido em três partes, além de introdução, considerações finais e referências. A primeira parte aborda as tecnologias de informação e comunicação no ensino e aprendizagem das Instituições de Ensino Superior, a segunda, o processo de inter- nacionalização curricular e a terceira, o uso das tecnologias de informação e comunicação nos cursos de graduação como instrumento de internacionalização curricular.

\section{AS TICs NO ENSINO SUPERIOR}

Em face de um intenso processo de globalização, de internacionalização de capitais e reestruturação produtiva, as exigências de uma melhor qualificação de profissionais para o mercado de trabalho estão cada vez maiores. Conforme Torres, Pimenta e Kerbauy (2017), tais situações têm gerado o aumento das demandas de necessidades educacionais no sentido de melhorar a capacitação da população de um modo geral. Nesse cenário, destacam-se, segundo os autores, a importância dos cursos de graduação e a sua procura, e até os de pós-graduação, como os mestrados profissionais, os MBA e outros.

Torres, Pimenta e Kerbauy (2017) também enfatizam que as Instituições de Ensino Superior (IES), lócus de formação, atentas a essas demandas de inserção de profissionais no mercado de trabalho, tentam dar conta, especificamente, do desenvolvimento de um aprendizado que possa envolver o manejo de informações, a apropriação de conhecimentos abstratos, a capacidade de análise e síntese, as capacidades de socialização, as habilidades de lidar em equipes interculturais e com atividades integradas. Percebe-se que toda essa formação está vinculada ao comprometimento com a produção de novos conhecimentos, com a inovação e o desenvolvimento da capacidade de adaptar-se às mudanças.

Observa-se, que, na atual estrutura social brasileira, é quase impossível imaginar bancos operando sem tecnologia da informação, da mesma forma que é impossível as Universidades e faculdades não considerarem em suas metodologias, em seus currículos, o uso eficaz da tecnologia. Essas instituições devem contribuir, em todas as instâncias, para o "letramento digital", para a inclusão tecnológica dos alunos no sentido de promover a justiça social e a democratização do acesso às novas tecnologias. As instituições de ensino, também, por sua vez, devem criar mecanismos para que docentes e 
discentes tenham acesso a equipamentos, softwares e outras tecnologias de telecomunicações para agregar no desenvolvimento pessoal e principalmente profissional dos mesmos.

Entretanto, há vários problemas existentes na relação entre as TIC e as Instituições de ensino superior, tais como: inadequação dos modelos pedagógicos adotados; dificuldades de integração curricular; falta de familiaridade do docente com as TIC no ensino; e ausência de processos de avaliação adequados. (TORRES, PIMENTA E KERBAUY, 2017). As mais modernas tecnologias de informação e comunicação exigem uma reestruturação ampla do sistema educacional de forma geral e não apenas a alteração dos objetivos, dos procedimentos e das metodologias de ensino.

Nesse contexto, Kenski (2003, p.87) aponta para a necessidade de uma reorganização das políticas organizacionais, da gestão e das formas de avaliação da educação de maneira geral e não apenas as mudanças dos métodos pedagógicos e das disciplinas a partir da utilização efetiva das redes no ensino. Trata-se de um caminho sem volta, um longo percurso para atualizações das metodologias, em especial no que tange à promoção de ações práticas de disseminação de TICs nas IES com a finalidade de melhorar a qualidade do processo ensino e aprendizagem, entendendo que o letramento digital é uma necessidade em decorrência da utilização frequente dessas tecnologias. Professores e alunos precisam se apropriar crítica e criativamente da tecnologia, dando-lhe significados e funções, em vez e consumi-la passivamente.

\section{A INTERNACIONALIZAÇÃO CURRICU- LAR}

Conforme Moreira e Ramos (2015), nossa vida contemporânea está, fundamentalmente, constituída por uma grande gama de mobilidades: de pessoas, de bens, de serviços e de informação. $\mathrm{O}$ acesso a todas essas possibilidades deveria ser garantido a todos, indistintamente.
"A mobilidade galga ao mais alto nível dentre os valores cobiçados- e a liberdade de movimentos, uma mercadoria sempre escassa e distribuída de forma desigual, logo se torna o principal fator estratificador de nossos tardios tempos modernos ou pós-modernos. (...) Ser local num mundo globalizado é sinal de privação e degradação social. (...) Uma causa específica de preocupação é a progressiva ruptura de comunicação entre as elites extraterritoriais cada vez mais globais e o restante da população, cada vez mais 'localizada'. (BAUMAN, 1999, p. 8).”

A intenção passa a ser, então, que o currículo promova uma compreensão intercultural, incentive uma perspectiva internacional e ajude os estudantes a melhor entender o caráter complexo e diverso do ambiente global (Rizvi, 2010), uma vez que os centros de produção de significado e valor são hoje "extraterritoriais", supranacionais e se mostram pouco dependentes de restrições locais.

Leask, em 2009, em um artigo do The Journal of Studies in International Education, Revista de Estudos do Ensino Internacional, defini um currículo internacionalizado como aquele que "envolverá os estudantes com a pesquisa internacionalmente informada e a diversidade linguística e cultural, além de propositalmente desenvolver suas perspectivas interculturais e internacionais como cidadãos e profissionais globais". (LEASK, 2009, p. 208)

Essa definição enfatiza o engajamento dos estudantes no processo de aprendizado e por meio desse desenvolvimento sistemático (intencional) dos resultados de aprendizado interculturais e internacionais. A definição enfoca a necessidade de ir além das abordagens de internacionalização do currículo com base no conteúdo, ou isolado, ótimas experiências e atividades para alguns alunos, que não fornecem evidências de resultados de aprendizagem.

Além disso, é importante distinguir, segundo a autora, um currículo internacionalizado, conforme definido acima, e o processo da internacionalização do currículo. O processo de internacionalização do currículo centra a atenção no ensino, aprendizado e avaliação, bem como no conteúdo: "a internacionalização do currículo é a incorporação de uma dimensão 
intercultural e internacional no conteúdo, assim como o ensino, aprendizado, instrumentos de avaliação e serviços de suporte de um programa de estudo". (LEASK, 2009, p. 208)

Essa distinção entre produto (currículo internacionalizado) e processo (internacionalização do currículo) ajuda a distinguir entre os fins e os meios, uma fonte de confusão permanente, conforme evidenciado por exemplo, por declarações que consideram os programas de mobilidade como evidência da internacionalização do currículo. Os programas de mobilidade, segundo Leask (2009), são meios possíveis pelos quais um pequeno número de estudantes poderão atingir resultados interculturais e internacionais de aprendizagem desejados.

O trabalho recente de Leask, Internationalizing the curriculum, publicado em 2015, considera que a internacionalização do currículo está sendo adotada não apenas por meio do currículo formal, mas também por meio do currículo informal.

O currículo formal, de acordo com Leask (2009), pressupõe o desenvolvimento de programas sequenciados de atividades de ensino-aprendizagem e de experiências organizadas por áreas de conhecimento, por tópicos e recursos, cujos objetivos são avaliados de diferentes formas, incluindo exames e vários tipos de trabalhos e outras atividades práticas em torno de um conteúdo definido.

Quando se refere ao currículo informal, tem-se as diversas atividades extracurriculares que ocorrem no campus, as atividades opcionais que não fazem parte dos requisitos formais da graduação, que, no entanto, contribuem para, de várias formas, definir a cultura do campus e, portanto, são uma parte importante do contexto em que o currículo formal é apresentado e utilizado no decorrer da disciplina.

A definição mais frequentemente citada do processo de internacionalização do currículo de Leask, concentra-se no currículo formal e avaliável: "A incorporação de uma dimensão internacional e intercultural na preparação, entrega e resultados de um programa de estudos" (LEASK, 2009, p. 209).
A autora destaca a importância da cuidadosa construção dos ambientes de aprendizagem e faz referência específica aos processos de ensino, aprendizagem e avaliação, aceitando assim sua importância na entrega do currículo internacionalizado.

Uma nova definição torna isso ainda mais explícito e atualiza a definição de 2009:

“A internacionalização do currículo é a incorporação de dimensões internacionais, interculturais e/ ou globais no conteúdo do currículo, bem como os resultados da aprendizagem, tarefas de avaliação, métodos de ensino e serviços de apoio de um programa de estudo". (LEASK, 2015, p.9).

Esta pesquisa toma como base essa definição de internacionalização do currículo de Leask (2015) e destaca, a seguir, a utilização da tecnologia de informação e comunicação como instrumento de internacionalização curricular "em casa"1 (at home) de acordo com estudos de Betty Leask, Jos Bellen e Elspeth Jones, buscando verificar a possibilidade de uma internacionalização que alcance todos os estudantes, pois a internacionalização além das fronteiras (abroad) é acessível apenas para um pequeno e restrito grupo de estudantes.

\section{TICS E A INTERNACIONALIZAÇÃO CURRICULAR}

O uso de TICs para transmitir programas de educação não necessariamente auxilia a internacionalização, mas oferece uma variedade de oportunidades para todos estudantes e funcionários. (LEASK, 2004).

Segundo Duke (2002), as TICs podem ser usadas para auxiliar formas de aprofundamento da internacionalização, mas o autor também destaca as armadilhas associadas ao seu uso, argumentando que embora elas tenham muito potencial para fortalecer e intensificar a internacionalização, esse não é 'um processo natural ou automático'.

\footnotetext{
${ }^{1}$ A expressão "em casa", neste estudo, é utilizada para referir-se aos estudos que acontecem dentro do localidade de origem dos discentes.
} 
Então, como nós podemos usar as TICs para nos auxiliar alcançar os resultados de internacionalização? A internet pode ser utilizada, por todos estudantes, para acessar informações, comunicar-se com professores, interagir e colaborar com outras escolas e alunos de todo mundo, significando que a distância e o tempo não são mais barreiras para exposição e conhecimento internacional por nenhum estudante com acesso a um computador e a um modem. Todos os estudantes podem potencialmente ter uma experiência internacional se as TICs são usadas para internacionalizar ambos: o conteúdo e a abordagem para ensino e aprendizagem no currículo.

Jos Bellen e Elspeth Jones (2015) destacam uma variedade de instrumentos que podem ser usados para internacionalizar o ensino e a aprendizagem: literatura internacional comparativa, palestras de grupos culturais locais ou empresas internacionais, palestrantes convidados de universidades internacionais parceiras, estudo de casos e práticas internacionais ou, cada vez mais, aprendizado digital e on-line de colaboração. As soluções baseadas em tecnologia podem garantir acesso igualitário a oportunidades de internacionalização para todos os alunos.

A interação online pode ser uma valiosa ferramenta para aumentar as oportunidades para estudantes de interação entre culturas. Além disso, quando os objetivos de internacionalização são explicitados, é mais fácil projetar tarefas on-lines que irão auxiliar os alunos a atingilos.

Essas conclusões são sustentadas por dois exemplos de internacionalização online em duas diferentes áreas de disciplinas, pesquisadas por Leask (2004). Em um curso de ciência da saúde e de fisioterapia.

Estes exemplos ilustram o potencial das TICs para auxiliar todos os estudantes a alcançarem uma gama de resultados de internacionalização. Pelo uso simples de ferramentas on-line (e-mail, a web site, grupos de discussão online) para interagir por meio das fronteiras nacionais e culturais para pesquisa e representação de outras perspectivas culturais e nacionais.
Embora as TICs possam ser usadas para aprendizagem de alunos internacionais, segundo Leask (2004), esse uso na entrega de um currículo representa desafios para os docentes e para aqueles que trabalham com eles. Embora as TICs ofereçam oportunidades únicas e ricas para internacionalização curricular, os docentes são frequentemente pouco familiarizados com esses potenciais ou se sentem desconfortáveis com o uso delas como ferramentas de ensino e aprendizagem, e alguns são desinteressados para investigar e experimentá-las.

Leask (2004) também ressalta que a equipe precisa se concentrar nos princípios do bom ensino tão bem quanto utilizar ambientes on-line para internacionalizar o ambiente de ensino e a experiência da aprendizagem. Conforme a autora, há muitos exemplos de tecnologias de informação e comunicação sendo usadas em programas de uma forma que não melhora o ensino e a aprendizagem. Por exemplo, o despejo de grande quantidade de textos dentro de sites que estudantes devem primeiro acessar e então imprimir antes que eles possam acrescentar muitos poucos valores para experiência de aprendizagem. Planejar um currículo para internacionalização é um processo complexo, exige atenção para os princípios habituais de uma boa aprendizagem dentro de um novo ambiente online. É, portanto, importante que docentes acadêmicos desenvolvam uma equipe de assistência, para, efetivamente e estrategicamente, utilizar ferramentas online que estejam disponíveis para auxiliar alunos na realização desejada de resultados de internacionalização, sem serem desencaminhados no uso de ferramentas tecnológicas para seus objetivos próprios. É necessário planejamento online de atividades de ensino e aprendizagem, desenvolvimento profissional adequado e serviços para auxiliar estudantes alcançarem resultados de internacionalização. (LEASKY, 2004).

A conquista de metas de internacionalização também exige estratégias de apoio aos alunos, segundo Leask. O apoio precisa ser focado em duas principais áreas: aprendizagem 
online e comunicação intercultural. As habilidades e competências necessárias para uma eficaz aprendizagem em um ambiente online inclui competências técnicas exigidas para participar em um grupo de debate online e pesquisar informações na $\mathrm{Web}$. Mas a participação em uma discussão online também requer um alcance de outras competências e entendimentos incluindo, por exemplo, um entendimento do público e o contexto e uma habilidade para expressar ideias e opiniões claramente e sucintamente na escrita. Nem todos os alunos terão essas habilidades ou serão capazes de adquiri-las sem assistência, precisarão de auxílio para alcançar o resultado desejado.

Há interseções entre três elementos críticos na internacionalização - resultados de internacionalização, o planejamento curricular e o uso de TICs. As interseções destes três elementos críticos fornecem ricas oportunidades e uma ampla gama de opções de internacionalização do currículo (LEASK, 2004). O programa de estudos, nesta área, incentivará explicitamente estudantes desenvolverem perspectivas e compromisso ativamente na aprendizagem intercultural por meio da comunicação com pessoas de sua própria e outras culturas online e face a face.

\section{CONSIDERAÇÕES FINAIS}

As condições institucionais, nacionais, regionais e globais estão em constante mutação e sujeitas a diferentes interpretações em diferentes disciplinas por diferentes equipes e indivíduos. Os professores precisam retornar a ele, como parte da revisão do programa regular, levando-se em consideração o contexto institucional, regional, nacional e mundial no qual o programa é entregue. Em função do rápido ritmo de mudança em todos os contextos, é improvável que a tarefa de internacionalizar o currículo seja completada.

A internacionalização do ensino é muito mais do que mobilidade de estudantes e docentes. Uma instituição educacional internacionalizada com êxito deve proporcionar uma expe- riência educacional internacional para todos seus alunos, em um ambiente que oferece suporte e inclui todos os estudantes.

As tecnologias de informação e comunicação podem ser usadas, efetivamente, para auxiliar estudantes no desenvolvimento de perspectivas internacionais, interagindo com pessoas de outras culturas, e ativamente envolvidos em uma aprendizagem intercultural.

Contudo, os estudantes precisam ser recompensados pela realização dos objetivos nestas áreas através de um sistema de avaliação formal. Além disso, é importante uma forte estrutura de desenvolvimento profissional e um serviço de suporte aos estudantes no uso das TICs para alcançarem um resultado de internacionalização.

Assim, precisa-se, em função da globalização e do desenvolvimento da tecnologia de informação e comunicação, de uma educação que vá além do diálogo intercultural local ou nacional e possibilite, também, o diálogo intercultural global, utilizando recursos tecnológicos de informação e comunicação, hoje comumente usados na sociedade. Além disso, é importante atentar-se nesse processo que essa troca não envolve apenas intenções democráticas e supostamente neutras. Relações de poder permeiam todo o processo e não podem ser secundarizadas. Busca-se, assim, uma educação que motive uma "ação no mundo", a participação na sociedade local, nacional e global.

\section{REFERÊNCIAS BIBLIOGRÁFICAS}

BAUMAN, Zygmunt; PENCHEL, Marcus. Globalização: as consequências humanas. Rio de Janeiro: Zahar, 1999.

BEELEN, Jos; JONES, Elspeth. Redefining Internationalization at home. In: CURAJ, A.; MATEI, L.; PRICOPIE, R.; SALMI, J.; SCOTT, P. The European Higher Education Area: Between Critical Reflections and Future Policies. London: Springer, 2015. e-Book. Disponível em: <www.springer.com $>$. Acesso em: $01 \mathrm{dez} 2016$. 
CASTELLS, M. Para o estado-rede: e era da informação. In: BRESSER-PEREIRA, L. C.; SOLA, L.; WILHEIM, J. (Org.). Sociedade e Estado em transformação. São Paulo: Editora Unesp, 1999.

DUKE, C. Cyperbole, commerce, and internationalisation: Desperate hope and desperate fear. Journal os Studies in International Education, 6(2), 93-113.

LEASK, B. Internationalisation Outcomes for All Students Using Information and Communication Technologies (ICTs). Journal of Studies in International Education, 2004, 336-351.

KENSKI, Vani Moreira. Tecnologias e ensino presencial e a distância. 3. ed. Campinas: $\mathrm{Pa}-$ pirus, 2003.

LEASK, B. Using formal and informal curriculum to improve interactions between home and international students. Journal of Studies in International Education, 2009, 205-221.

LEASK, Betty. Internationalizing the curriculum. Routledge, 2015.

MORAN, José Manuel, MASSETO, Marcos T., BEHRENS Marilda Aparecida. Novas Tecnologias e mediações pedagógicas. Campinas, SP. Papirus, 2012.

MOREIRA, Antonio F. B.; RAMOS, Rosane K. Currículo, Internacionalização e Cosmopolitismo. In: Currículo, Globalização e Cosmopolitismo: Diálogos entre o Local e o Global. Portugal: De Fato Editores, 2015

MOREIRA, Antonio Flavio B. O atual processo de internacionalização do campo: estratégias $e$ desafios. Educação, Sociedade \& Culturas, n. 37, p. 45-61, 2012.

SILVA, Marco. Sala de aula interativa: a educação presencial e a distância em sintonia com a era digital e com a cidadania. In: CONGRESSO
BRASILEIRO DA COMUNICAÇÃO, 24, 2001, Campo Grande. Anais do XXIV Congresso Brasileiro da Comunicação, Campo Grande: set. 2001.

TORRES, Ana Paula; PIMENTA, Leny André; KERBAUY, Maria Teresa Miceli. O uso efetivo das tecnologias de informação e comunicação (TIC) no ensino superior. Conhecimento \& Diversidade, v. 9, n. 18, p. 123-143, 2018. 